\title{
A clonal theory of parasitic protozoa: The population structures of Entamoeba, Giardia, Leishmania, Naegleria, Plasmodium, Trichomonas, and Trypanosoma and their medical and taxonomical consequences
}

(phylogenetic classification/linkage disequilibrium/recombination/Chagas disease/malaria)

\author{
Michel Tibayrenc*†, Finn KJellberg ${ }^{\ddagger}$, and Francisco J. Ayala $\S$ \\ *Laboratoire de Génétique des Parasites et des Vecteurs, Institute Français de Recherche pour le Développement en Coopération, BP 5045,34032 Montpellier \\ Cedex, France; ${ }^{\dagger}$ Centre D'Etudes Phytosociologiques et Ecologiques, Centre National de la Recherche Scientifique, Route de Mende, 34033 Montpellier, \\ France; and ${ }^{\S}$ Department of Ecology and Evolutionary Biology, University of California, Irvine, CA 92717
}

Contributed by Francisco J. Ayala, December 15, 1989

\begin{abstract}
We propose a general theory of clonal reproduction for parasitic protozoa, which has important medical and biological consequences. Many parasitic protozoa have been assumed to reproduce sexually, because of diploidy and occasional sexuality in the laboratory. However, a population genetic analysis of extensive data on biochemical polymorphisms indicates that the two fundamental consequences of sexual reproduction (i.e., segregation and recombination) are apparently rare or absent in natural populations of the parasitic protozoa. Moreover, the clones recorded appear to be stable over large geographical areas and long periods of time. A clonal population structure demands that the medical attributes of clones be separately characterized; ubiquitous clones call for priority characterization. Uniparental reproduction renders unsatisfactory Linnean taxonomy; this needs to be supplemented by the "natural clone" as an additional taxonomic unit, which is best defined by means of genetic markers.
\end{abstract}

It has recently been shown in the laboratory that some medically important protozoa may undergo sexual recombination. This has been shown by means of genetically marked stocks in Trypanosoma brucei, the agent of African trypanosomiasis (1-3), Plasmodium falciparum, one of the agents of malaria (4), and Entamoeba histolytica, the agent of human amoebiasis (5).

Various authors have, moreover, postulated that genetic recombination occurs also in natural populations of $T$. bruce $i$ (6-8), P. falciparum (9), and Leishmania $(10,11)$. Outbreeding within the species as a whole has been proposed for $T$. brucei $(6,7)$ and $P$. falciparum $(9)$, and it has been suggested that it may indeed be the case for many parasitic protozoa (12).

Yet, the extent to which genetic recombination occurs in natural populations remains to be determined-in the organisms for which it has been demonstrated in the laboratory as well as in other parasitic protozoa. We investigate herein this question by analyzing published data on the biochemical variability of natural populations of these parasites. We use the methods of population and evolutionary genetics, an approach that we have previously followed in our studies of Trypanosoma cruzi, the agent of Chagas disease $(13,14)$.

\section{CRITERIA FOR CLONALITY}

The two fundamental genetic consequences of sexual reproduction are segregation and recombination. Evidence of their

The publication costs of this article were defrayed in part by page charge payment. This article must therefore be hereby marked "advertisement" in accordance with 18 U.S.C. $\$ 1734$ solely to indicate this fact. absence in natural populations is, therefore, evidence that sexual reproduction is lacking. Segregation is a property predicated of alleles at a single locus, whereas recombination refers to relationships between alleles at different loci. Table 1 lists the criteria we used in our survey as evidence of clonal, rather than sexual, reproduction. Criteria a-c are evidence that segregation is lacking; these criteria apply, of course, only to diploid organisms. Table 1 lists four additional criteria, d-g, which refer to genetic recombination between loci and are independent of ploidy. Criteria $d, f$, and $g$ have been used as evidence of clonality in bacterial populations $(15,16)$, and criterion e has been invoked as evidence that genetically distinct strains may be evolving separately in $T$. brucei (17).

We assume for our statistical tests as well as other purposes that genetically homogeneous stocks represent a single-individual sample and that mixtures of two different genotypes harbor two individuals (18).

\section{RESULTS}

The results summarized in Table 1 are incompatible with outbreeding as the common mode of reproduction for every one of the organisms surveyed. One or more strong indicators of clonality exist for each species. The statistical tests are highly significant in almost every case where the sample numbers are sufficiently large for meaningful tests.

Evidence Against Segregation: Tests That Depend on Ploidy Level. Criterion a: Fixed heterozygosity. Individuals often exhibit heterozygosity at one or more loci-the same loci again and again in independently sampled individuals. Fixed heterozygosity is incompatible with meiotic segregation.

We repeatedly observed the phenomenon of fixed heterozygosity in our studies of $T$. cruzi (14). It is also a common phenomenon in the other parasites surveyed here. In $T$. brucei rhodesiense (19), a zymodeme (i.e., a genotype as determined by enzyme patterns in gels) heterozygous at each of the same four loci was sampled five times from two different locals in Kenya. In $T$. congolense (20), zymodeme 29, which is heterozygous for Mdh, Sod, and Gpi, was independently sampled from two different species of tsetse flies in Uganda and in Kenya. In Leishmania, heterozygous patterns are scarcely recorded in general, but numerous instances of fixed heterozygosity are apparent in L. tropica (21). Within the genus Naegleria (22), all three stocks of $N$. gruberi exhibited fixed heterozygosity at one locus; all stocks of $N$. fowleri and $N$. australiensis exhibited heterozygosity at two loci; and three of the stocks of $N$. australiensis (isolated

Abbreviation: RFLP, restriction fragment length polymorphism

†To whom reprint requests should be addressed. 
Table 1. Criteria of clonality

\begin{tabular}{clc}
\hline Criterion & \multicolumn{1}{c}{ Description } & Species* \\
\hline & \multicolumn{1}{c}{ Segregation (within locus) } \\
a & Fixed heterozygosity & $5,7,10-12$ \\
b & Absence of segregation genotypes & $3-6,10-12$ \\
c & Deviation from Hardy-Weinberg & 10,12 \\
& expectations & \\
& $\quad$ Recombination (between loci) & $1-12$ \\
d & Identical genotypes widespread & $1-6,8,10-12$ \\
e & Absence of recombinant genotypes & 12 \\
f & Linkage disequilibrium & $6,10,12$ \\
g & Correlation between two independent & \\
& sets of genetic markers & \\
\hline
\end{tabular}

*The numbers indicate the species for which a given criterion has been satisfied. 1, E. histolytica; 2, Giardia sp.; 3, Leishmania donovani/infantum; 4, Leishmania major; 5, Leishmania tropica; 6, Leishmania Old World; 7, Naegleria sp.; 8, P. falciparum; 9, Trichomonad sp.; 10, T. brucei s.l.; 11, Trypanosoma congolense; $12, T$. cruzi. Ploidy is unknown for species 1 and $2 ; 8$ is considered haploid; all others are considered diploid. Criteria a-c apply only to diploid organisms. Criteria $\mathbf{d}$ and $\mathrm{g}$ refer to the spatial and temporal stability of clones.

in France, Italy, and Australia) exhibited fixed heterozygosity at four loci.

Criterion b: Absence of segregation genotypes. Sexual reproduction, through the processes of meiotic segregation and fertilization, yields homozygous and heterozygous individuals for the various alleles present at a given locus. If some of the possible genotypes at a locus are absent or strongly underrepresented, this suggests that reproduction may not be sexual. Fixed heterozygosity is a particularly obvious case of absence of segregation genotypes.

We have pointed out earlier numerous instances of missing single-locus genotypes in $T$. cruzi $(14,23)$. Other Trypanosoma cases can be cited. For example, in a large and geographically diversified sample of 160 stocks of $T$. brucei s.l., missing genotypes include Pgm $a / a$ and $a / b, M d h c / d$, and also Asat $a / e$ and $c / e$ (24). In $T$. congolense, examples of missing genotypes are $P g m f / f$ and $a / a, M d h h / h$ and $a / f$, and Gpi $a / a$, among many others (20).

The absence of single-locus genotypes is particularly striking in Old World Leishmania, where no heterozygotes are found at all in some instances in spite of extensive samplings. In $L$. donovani, for example, the missing genotypes include Mdh 100/112, Gpi 86/100, and also Np-1 100/130, 100/140, and 100/150 (25); in L. major, Me 88/108, Idh 90/130, and Np-1 400/500 (26); in L. tropica, Glud 80/95, Dia-1 100/120, and also Mdh 100/112 and 100/118 (27).

Criterion c: Deviation from Hardy-Weinberg expectations. Strong departures from Hardy-Weinberg expectations within a particular geographical area have been pointed out for $T$. cruzi (23), as well as for a limited data set of $T$. brucei rhodesiense from Kenya (19).

The strength of the evidence presented under criteria a-c depends on the genes being present in diploid condition (e.g., the appearance of fixed heterozygosity could be due to gene duplication). This limitation does not apply to criteria $\mathbf{d}-\mathrm{g}$, which are independent of ploidy level.

Evidence Against Recombination: Tests Independent of Ploidy Level. Criterion d: Overrepresented, ubiquitous multilocus genotypes. When all loci studied in a particular parasite are jointly considered, it is quite apparent that multilocus combinations that would be expected with fairly high frequencies if recombination would occur are missing, whereas others are highly overrepresented. Moreover, the same overrepresented genotypes are often found in different, even widely separated, localities and at different times, many years apart in some cases. This pervasiveness and persistence of a few improbable genotypes are best interpreted as consequences of clonal reproduction of a few, highly successful genotypic arrays.

The extent to which predominant genotypes are overrepresented can be quantitatively evaluated by calculating the probability, $P$, of observing as many or more individuals with a particular genotype as actually observed in the sample:

$$
P=\sum_{i=m}^{n} \frac{n ! \cdot x^{i} \cdot(1-x)^{n-i}}{i ! \cdot(n-i) !}
$$

where $x=$ probability of the multilocus genotype under the null hypothesis of free recombination, estimated by multiplying the observed frequency of the single-locus genotypes; $n=$ number of individuals sampled; and $m=$ number of individuals in the sample with the particular genotype. The results (Table 2) are highly significant in virtually every case, showing that some multilocus genotypes occur at much higher frequencies than would be expected under the null hypothesis. The one exception is $T$. brucei "non-gambiense," where the two available samples are very small (16 and 9 individuals). Yet, even in this case, the probabilities become highly significant if the two samples are combined. We have not included $T$. cruzi in Table 2 , because our extensive data on this species have been analyzed elsewhere $(13,14,18)$.

Predominant genotypes are not only overrepresented in particular localities but are also widespread over extensive geographical areas and persist over long periods of time. We shall cite but a few examples. Two genotypes (each heterozygous at four loci) of $T$. brucei $(8,19)$ were independently sampled from various places ( 3 and 5 times, respectively), although they were expected less than once $(0.23$ times for one and 0.07 times for the other). Numerous additional examples of ubiquitous overrepresented genotypes occur in the extensive studies on $T$. brucei s.l. (24) and T. congolense (20).

In Leishmania, zymodeme MON 1 is a striking example of an ubiquitous genotype; it is predominant in the Old World as well as in Latin America $(28,29)$. In $P$. falciparum (30), the single genotype Gpi 1/Ada 1/Ldh 1/Pep 1 was found 10 times in a total sample of 17 (expected number: 5), in five countries: Gambia, Senegal, Tanzania, Vietnam, and China. Another genotype (Gpi 2/Ada 1/Ldh 1/Pep 2) was found 3 times (expected number: 0.28), in Ghana, Zaïre, and Indochina. With the sensitive technique of two-dimensional electrophoresis, two $P$. falciparum laboratory clones from Thailand appeared completely identical to two other laboratory clones isolated in another town of the same country, $280 \mathrm{~km}$ apart (31). In E. histolytica, zymodemes I, II, and III were each repeatedly sampled in both Canada and South Africa $(32,33)$. In Trichomonas vaginalis, six genetically identical strains have been recorded: five were recently isolated and the sixth was isolated in 1939 (34). In Trichomonas foetus, four genetically identical strains were isolated in Canada, California, and Utah (34).

In Giardia (35), zymodeme 1 was sampled 10 times from a variety of locals in western Australia and once in southern Australia; zymodeme 4 was sampled 7 times, 5 times from humans (in western Australia, Queensland, and Papua New Guinea) and 2 times from cats (western Australia and Oregon). Another study (36) of the same parasite sampled zymodeme 1, which seems identical to the just-mentioned zymodeme 4, from a man in England and one in Maryland, and from one cat in Oregon. A restriction fragment length polymorphism (RFLP) study revealed complete identity among Giardia stocks isolated from humans in Afghanistan, Ecuador, and Puerto Rico; from a cat in the U.S.; and from a beaver in Canada (37). In N. australiensis, a particular 
Table 2. Statistical tests for overrepresentation or absence of genotypes

\begin{tabular}{|c|c|c|c|c|c|c|c|c|c|c|c|}
\hline \multirow[b]{2}{*}{ Organism } & \multirow[b]{2}{*}{ Ref. } & \multicolumn{2}{|c|}{ Number sampled } & \multicolumn{8}{|c|}{ Probability of test } \\
\hline & & Individuals & Loci & A & B & $\mathrm{C}$ & D & $\mathbf{E}$ & $\mathbf{F}$ & $\mathbf{G}$ & $\mathbf{H}$ \\
\hline \multicolumn{12}{|l|}{ E. histolytica } \\
\hline Canada sample & 29 & 120 & 3 & $10^{-3}$ & ND & $10^{-3}$ & ND & $10^{-4}$ & ND & $10^{-4}$ & ND \\
\hline South Africa sample & 30 & 31 & 3 & $10^{-2}$ & ND & 0.008 & ND & $10^{-3}$ & ND & 0.03 & ND \\
\hline Giardia sp. & 36 & 30 & 6 & $10^{-12}$ & ND & $10^{-3}$ & ND & $10^{-11}$ & ND & $10^{-4}$ & ND \\
\hline L. donovani/infantum & 25 & 146 & 8 & $10^{-6}$ & $10^{-23}$ & $10^{-4}$ & $10^{-4}$ & 0.01 & $10^{-7}$ & $10^{-4}$ & $10^{-4}$ \\
\hline L. major & 26 & 35 & 13 & $10^{-15}$ & $10^{-41}$ & $10^{-4}$ & $10^{-4}$ & $10^{-4}$ & $10^{-15}$ & $10^{-4}$ & $10^{-4}$ \\
\hline L. tropica & 27 & 29 & 11 & $10^{-23}$ & $10^{-54}$ & $10^{-4}$ & $10^{-4}$ & $10^{-4}$ & $10^{-13}$ & $10^{-4}$ & $10^{-4}$ \\
\hline \multicolumn{12}{|l|}{ Leishmania, } \\
\hline Old World as a whole & 31 & 192 & 15 & $10^{-61}$ & $10^{-77}$ & $10^{-4}$ & $10^{-4}$ & $10^{-53}$ & $10^{-68}$ & $10^{-4}$ & $10^{-4}$ \\
\hline \multicolumn{12}{|l|}{ P. falciparum } \\
\hline All loci combined & 33 & 17 & 4 & 0.01 & 0 & 0.01 & 0 & 0.003 & 0 & 0.01 & 0 \\
\hline Adenosine deaminase/ & & & & & & & & & & & \\
\hline lactate dehydrogenase & 33 & 17 & 2 & $10^{-4}$ & 0 & $10^{-3}$ & $\mathbf{0}$ & $\mathbf{0}$ & 0 & 0.02 & 0 \\
\hline \multicolumn{12}{|l|}{ T. brucei non-gambiense } \\
\hline Total sample & 8 & 25 & 4 & 0.003 & $10^{-4}$ & 0.01 & 0.005 & $10^{-4}$ & NS & $10^{-3}$ & 0.002 \\
\hline West Africa sample & 8 & 16 & 4 & NS & NS & NS & NS & NS & NS & NS & NS \\
\hline East Africa sample & 8 & 9 & 4 & $10^{-3}$ & $10^{-3}$ & NS & NS & ND & ND & NS & NS \\
\hline T. brucei rhodesiense & 20 & 11 & 10 & $10^{-3}$ & $10^{-8}$ & $10^{-3}$ & $10^{-4}$ & ND & ND & 0.002 & $10^{-4}$ \\
\hline$T$. congolense & 21 & 114 & 6 & $10^{-3}$ & ND & 0.006 & ND & $10^{-3}$ & ND & $10^{-3}$ & ND \\
\hline
\end{tabular}

The values given are equal to or greater than the probability of sampling as many or more individuals of the most common genotype (A and $\mathrm{B}$ ) or any genotype (C and D) as observed of the most common genotype; as many individuals or more of the second most common genotype as actually observed ( $E$ and $F)$; as few different genotypes as actually observed ( $G$ and $H)$. The tests are made assuming either haploidy (A, C, E, and $G)$ or diploidy (B, D, F, and H). NS, not significant; 0 , test not possible, because it assumes diploidy whereas the data are for haploid organisms $\mathrm{ND}$, not done either because of insufficient or unavailable data or because the zymograms are not satisfactorily interpretable. Tests A-F refer to criterion d of Table 1; $\mathrm{G}$ and $\mathrm{H}$ refer to criterion e. The markers used are DNA probes for T. cruzi non-gambiense and isozymes for all others.

genotype exhibiting heterozygosity at four loci was sampled in France, Italy, and Australia (23).

Criterion $e:$ Absence of recombinant genotypes. The numbers of different genotypes found in the parasite studies are much smaller than would be expected under the null hypothesis of regular outbreeding, given the size of the samples and the allelic frequencies observed. The discrepancy can be statistically tested by simple $\chi^{2}$ tests, but randomization procedures are more suitable (17). We composed a special Turbo Pascal program for our tests. The results, reported in Table 2, tests $\mathbf{G}$ and $H$, are statistically significant in virtually every case. The exceptions are the two small samples of $T$. brucei non-gambiense from West and East Africa; when these two samples are combined, the deficiency of multilocus genotypes becomes significant.

Unfortunately, we were unable to test statistically the large sample of $6000 \mathrm{E}$. histolytica stocks reported by Sargeaunt $e t$ al. (38), because the detailed geographic origins were not available. The deficiency of recombinant genotypes is in any case apparent: only 20 different genotypes (zymodemes), out of 144 possible, were recorded in this extensive sample.

Criterion $f$ : Linkage disequilibrium. Our detailed tests with $T$. cruzi exhibited values close to the maximum disequilibrium theoretically possible for the allele frequencies observed (18). We have not performed statistical tests for linkage disequilibrium in the other parasites, because the highly significant results reported in the previous two sections make superfluous these highly sensitive tests.

Criterion g: Correlation between two independent sets of genetic markers. Association between unrelated genetic markers provides evidence of clonal reproduction (16). Particularly strong evidence derives from the joint transmission of nuclear and nonnuclear genetic markers, as we have shown in $T$. cruzi, where there is a highly significant correlation between isozyme variability, controlled by nuclear genes, and kinetoplast DNA RFLPs, resident in an extranuclear organelle (39). We have recently found a statistically significant correlation between isozyme variability and RFLP of kinetoplast DNA also in the genus Leishmania (unpublished results).
In $T$. cruzi it has been recently shown that concordance exists between isozyme characterization and genomic DNA.DNA hybridization, although the sample was too small to allow statistical analysis (40). A correlation between isozyme polymorphism and nuclear DNA RFLPs has been found in samples of numerous Leishmania species from both the Old and the New World (41).

Recent studies $(8,42)$ of nuclear RFLPs in $T$. brucei s.l. have led to the separation of the stocks into gambiense and nongambiense taxa, interpreted as genetically isolated from each other. Regular outbreeding was, however, postulated to account for the high genetic variability scored among the nongambiense stocks. We have analyzed this latter group by determining the genetic distances that could be inferred from each of the two independent sets of DNA probes used by the authors. For one data set (42), we estimated distances from the phenetic tree published by the authors. For the other data set (8), we calculated distances from the allelic percent mismatch in pairwise comparisons between stocks. Undefined (infinite) distances were excluded from the analysis. The 291 pairwise comparisons between the two data sets yielded a highly significant correlation $(r=0.308, P<0.001)$, which could hardly be explained if outbreeding were the mode of reproduction of these parasites. It deserves pointing out that the gambiense group is fairly homogeneous for the two sets of probes, so that the correlation would have been even stronger if the gambiense data would have been incorporated into the analysis in order to consider T. brucei s.l. as a whole.

\section{DISCUSSION}

To our knowledge, this is the first time that a clonal population structure has been proposed for parasitic protozoa as a general working hypothesis buttressed by an extensive population genetics analysis. The hypothesis advanced here is not simply that these organisms can reproduce clonally, something well known to take place in the laboratory, or that the populations of these parasites are not fully panmictic, something known to be the case for all sorts of organisms. Rather, we are proposing that uniparental reproduction is, at 
least for the cases herein surveyed, predominant enough in natural populations to generate clones that are stable in space and time, even on an evolutionary time scale.

The lines of evidence that we have gathered are so convergent and consistent and the statistical results are so highly significant that clonality emerges as the most parsimonious hypothesis to account for the observed results. The strength of the population genetic analyses we have carried out may be highlighted by pointing out that a similar population genetics approach failed to yield the conclusion of clonal reproduction in the bacteria Neisseria gonorrhoeae and Pseudomonas aeruginosa (15), even though asexual reproduction must be frequent in these bacterial species.

Evidence that regular outbreeding may not always prevail had been pointed out earlier for some parasitic protozoa on the basis of limited evidence. In the genus Leishmania, the predominance of asexual reproduction was commonly accepted $(28,43)$, although never ascertained by means of genetic analyses of the sort we have developed. In T. brucei s.l., statistical evidence of a deficit of multilocus genotypes led to the conclusion that distinct strains might evolve independently (17), but it was not proposed that a clonal population structure would prevail throughout the whole taxon, nor were the consequences of such a hypothesis explored. Clonality was suspected for $\boldsymbol{P}$. falciparum but only on the basis of indirect evidence from a few antigen markers (44).

For some species of the genera Naegleria and Trichomonas, qualitative data such as fixed heterozygosity and repeated sampling of ubiquitous genotypes provide a sound basis for the hypothesis of clonality, although limited sampling forestalls statistical tests. In the case of $\boldsymbol{P}$. falciparum, it is unfortunate that only 17 multilocus genotypes can be properly evaluated (30), owing to the fact that isozyme data are generally reported separately for each locus. Nevertheless, the allelic frequencies estimated from the most extensive sampling available (45) yield statistical tests that are quite significant (Table 2), and the sample under survey is well diversified. Moreover, the allopatric discovery of genotypes that are identical with the sensitive technique of 2-dimensional electrophoresis (31) also favors clonality. Nevertheless, more extensive stock samplings and a broader range of genetical markers would be required to ascertain definitively our hypothesis in $\boldsymbol{P}$. falciparum. An alternative explanation for the isozyme results (17), also with important medical implications, would be the existence of several sexual sibling species within this taxon. It is also possible that uniparental and biparental lineages may coexist within this species, for which a sexual cycle has been a classical notion. Such coexistence has been frequently observed in some metazoan species $(46,47)$. The genus Naegleria, in which there is indication of sexual recombination for the species $N$. lovaniensis (22), could be another example of juxtaposition of crossbreeding and uniparental lineages.

More generally, the hypothesis of clonality does not rule out the possibility of occasional genetic recombination, but rather it indicates that such recombination is not important enough for altering significantly the prevailing pattern of clonal population structure. Moreover, such a hypothesis does not imply, as we have emphasized elsewhere (14), that the stocks characterized as identical on the basis of a few genetic markers are necessarily a completely homogeneous set, but rather that they are families of related clones. A broader range of genetic markers would uncover additional variability within each set of "identical" clones.

The general hypothesis of clonal population structure for parasitic protozoa is of considerable genetic and medical import. The implications of regular outbreeding have been stressed by several authors $(7,12,45)$. It would be impossible to characterize individual natural "strains," since there would be no stable genetic differences among the lineages of a given parasite. The implications of clonality are quite disparate. Each species can be usefully subdivided into meaningful strains (i.e., natural clones, stable in space and time). Priority in the investigation of medical characteristics should be given to those clones that are widespread and common. We have called attention to the existence of such predominant clones in $T$. cruzi and suggested that they be referred to as "major clones" (48).

Clonal population structure hinders the use of Linnean nomenclature for these parasitic protozoa, because of difficulties that arise with asexual species in general. Efforts to extend the Linnean taxonomy to the populational diversity found in these parasites have, indeed, been far from successful. The taxonomic issues cannot be explored in depth in the present paper, but a few examples will point out some problems.

Three subspecies of $T$. brucei have been named (namely, $T$. brucei brucei, T. brucei gambiense, and T. brucei rhodesiense), but these are probably simple "pathotypes." The taxon $T$. brucei appears as composed of numerous clones, some of which have become specialized to human hosts, particularly in West Africa. T. brucei gambiense "group 1" (49) appears to be a genetically homogeneous clone that would be just an instance of a successful, ubiquitous human-host clone.

Visceral leishmaniasis is mainly caused by a single clone (zymodeme MON 1; refs. 11 and 29), widespread in the Old World as well as in Latin America. In the Old World, it is a small component of the heterogeneous Leishmania infantum "complex" (28), but in the New World it has been classified as a distinct species, Leishmania chagasi.

We do not propose here that Linnean nomenclature be altogether repudiated in the case of parasitic protozoa, but rather that it be supplemented, particularly for medical purposes, with a more rigorous taxonomic unit, the natural clone. The clones, not the species as wholes, are the distinctive evolving units, the medical and epidemiological characteristics of which need to be ascertained. A similar situation occurs in bacteria. Indeed, population genetic studies of bacteria, initiated by Milkman (50), have elucidated the clonal population structure of natural populations of Escherichia coli as well as other species $(15,51)$.

Clones can be identified primarily by genetic markers, interpreted by means of population genetic considerations as we have advanced above and developed elsewhere $(13,14)$. The approach herein proposed calls for standardization of genetic labeling and other nomenclatural efforts and also of the statistical procedures for evaluating instances of genetic recombination that might bear on the long-term evolution of the clones.

We are grateful to the following scientists for their helpful comments about an earlier version of this manuscript: S. F. BrenièreCampana and F. Mathieu-Daudé (Institute Français de Recherche pour le Développement en Coopération, Montpellier, France); M. Clegg (University of California, Riverside, CA); P. Desjeux (World Health Organization, Geneva); J. C. Dujardin, J. P. Dujardin, and D. Le Ray (Institute of Tropical Medicine "Prince Leopold," Antwerp, Belgium); B. Levin and M. Riley (University of Massachusetts, Amherst, MA); A. Saura (University of Helsinki, Finland); and J. Theis (University of California, Davis, CA).

1. Jenni, L., Marti, S., Schweizer, J., Betschart, B., Le Page, R. W. F., Wells, J. M., Tait, A., Paindavoine, P., Pays, E. \& Steinert, M. (1986) Nature (London) 322, 173-175.

2. Paindavoine, P., Zampetti-Bosseler, R., Pays, E., Schweizer, J., Guyaux, M., Jenni, L. \& Steinert, M. (1986) EMBO J. 5, 3631-3636.

3. Sternberg, J., Tait, A., Haley, S., Wells, J. M., Le Page, R. W. F., Schweizer, J. \& Jenni, L. (1988) Mol. Biochem. Parasitol. 27, 191-201. 
4. Walliker, D., Quakyi, I. A., Wellems, T. E., McCutchan, T. F., Szarfman, A., London, W. T., Corcoran, L. M., Burkot, T. R. \& Carter, R. (1987) Science 236, 1661-1666.

5. Sargeaunt, P. G., Jackson, T. F. H., Wiffen, S. R. \& Bhojnani, R. (1988) Trans. R. Soc. Trop. Med. Hyg. 82, 862-867.

6. Tait, A. (1980) Nature (London) 287, 536-538.

7. Tait, A. (1983) Parasitology 86, 29-57.

8. Paindavoine, P., Zampetti-Bosseler, F., Coquelet, H., Pays, E. \& Steinert, M. (1989) Mol. Biochem. Parasitol. 32, 61-72.

9. Walliker, D. (1988) in Biology of Parasitism: A Molecular and Immunological Approach, eds. Englund, P. T. \& Sher, A. (Liss, New York), pp. 467-479.

10. Evans, D., Kennedy, W. P. K., Elbihari, S., Chapman, C. J., Smith, V. \& Peters, W. (1987) Parassitologia (Rome) 29, 165-173.

11. Rioux, J. A., Lanotte, G. \& Pratlong, F. (1986) in Leishmania: Taxonomie et Phylogenese: Applications Eco-Epidemiologiques (Coll. Int. CNRS/INSERM, Paris), pp. 139-142.

12. Thompson, A. \& Lymbery, A. (1988) New Sci. 29, 49-51.

13. Tibayrenc, M., Ward, P., Moya, A. \& Ayala, F. J. (1986) Proc. Natl. Acad. Sci. USA 83, 115-119.

14. Tibayrenc, M. \& Ayala, F. J. (1988) Evolution 42, 277-292.

15. Selander, R. K., Musser, J. M., Caugant, D. A., Gilmour, M. N. \& Whittam, T. S. (1987) Microbial Pathogen. 3, 1-7.

16. Miller, R. D. \& Hartl, D. L. (1986) Evolution 40, 1-12.

17. Cibulskis, R. E. (1988) Parasitology 96, 303-322.

18. Zhang, Q., Tibayrenc, M. \& Ayala, F. J. (1988) J. Protozool. 35, 81-85.

19. Tait, A., Barry, J. D., Wink, R., Sanderson, A. \& Crowe, S. J. (1985) Parasitology 90, 89-100.

20. Gashumba, J. K., Baker, R. D. \& Godfrey, D. G. (1988) Parasitology 96, 475-486.

21. Le Blancq, S. M. \& Peters, W. (1986) Trans. R. Soc. Trop. Med. Hyg. 80, 113-119.

22. Cariou, M. L. \& Pernin, P. (1987) Genetics 115, 265-270.

23. Tibayrenc, M., Echalar, L., Dujardin, J. P., Poch, O. \& Desjeux, P. (1984) Trans. R. Soc. Trop. Med. Hyg. 78, 519-525.

24. Gibson, W. C., Marshall, T. F. de C. \& Godfrey, D. (1980) Adv. Parasitol. 18, 175-246.

25. Moreno, G., Rioux, J. A., Lanotte, G., Pratlong, F. \& Serres, E. (1986) Leishmania: Taxonomie et Phylogenese: Applications Eco-Epidemiologiques (Coll. Int. CNRS/INSERM, Paris), pp. 105-119.

26. Maazoun, R., Pratlong, F., Lanotte, G. \& Rioux, J. A. (1986) Leishmania: Taxonomie et Phylogenese: Applications EcoEpidemiologiques (Coll. Int. CNRS/INSERM, Paris), pp. 119129.

27. Pratlong, F., Lanotte, G., Ashford, R. W. \& Rioux, J. A. (1986) Leishmania: Taxonomie et Phylogenese: Applications EcoEpidemiologiques (Coll. Int. CNRS/INSERM, Paris), pp. 129139.
28. Lanotte, G., Rioux, J. A. \& Serres, R. (1986) Leishmania: Taxonomie et Phylogenese: Applications Eco-Epidemiologiques (Coll. Int. CNRS/INSERM, Paris), pp. 27-40.

29. Desjeux, P., Le Pont, F., Mollinedo, S. \& Tibayrenc, M. (1986) Leishmania: Taxonomie et Phylogenese: Applications EcoEpidemiologiques (Coll. Int. CNRS/INSERM, Paris), pp. 411421.

30. Sanderson, A., Walliker, D. \& Molez, J. F. (1981) Trans. $R$. Soc. Trop. Med. Hyg. 75, 263-267.

31. Fenton, B., Walker, A. \& Walliker, D. (1985) Mol. Biochem. Parasitol. 16, 173-183.

32. Proctor, E. M., Wong, Q., Yang, J. \& Keystone, J. S. (1987) Am. J. Trop. Med. Hyg. 37, 296-301.

33. Sargeaunt, P. G., Williams, J. E., Jackson, T. F. H. G. \& Simjee, A. E. (1982) Trans. R. Soc. Trop. Med. Hyg. 76, 401-402.

34. Nadler, S. A. \& Honigberg, B. M. (1988) J. Parasitol. 74, 797-804.

35. Meloni, B. P., Lymbery, A. J. \& Thompson, R. C. A. (1988) Am. J. Trop. Med. Hyg. 38, 65-73.

36. Bertram, M. A., Meyer, E. A., Lile, J. D. \& Morse, S. A. (1983) J. Parasitol. 69, 793-801.

37. Nash, T. E., McCutchan, T., Keister, D., Dame, J. B., Conrad, J. D. \& Gillin, F. D. (1985) J. Infect. Dis. 152, 64-73.

38. Sargeaunt, P. G., Jackson, T. F. H. G., Wiffen, S., Bhojnani, R., Williams, J. E., Felmingham, D., Goldmeir, D., AllasonJones, E., Mindel, A. \& Phillips, E. (1987) Arch. Invest. Med. $18,69-75$.

39. Tibayrenc, M. \& Ayala, F. J. (1987) C. R. Hebd. Seances Acad. Sci. Ser. C 304, 89-92.

40. Castaneda, M., Craig, S. P. \& Castro, C. (1988) Comp. Biochem. Physiol. 91B, 707-710.

41. Beverley, S. M., Ismach, R. B. \& Pratt, D. M. (1987) Proc. Natl. Acad. Sci. USA 84, 484-488.

42. Paindavoine, P., Pays, E., Laurent, M., Geltmeyer, Y., Le Ray, D., Mehlitz, D. \& Steinert, M. (1986) Parasitology 92, 31-50.

43. Lainson, R. \& Shaw, J. J. (1986) Leishmania: Taxonomie et Phylogenese: Applications Eco-Epidemiologiques (Coll. Int. CNRS/INSERM, Paris), pp. 241-245.

44. Weber, J. L. (1988) Exp. Parasitol. 66, 143-171.

45. Walliker, D. (1985) Ann. Soc. Belge Med. Trop. 65, 69-77.

46. Parker, E. D., Selander, R. K., Hudson, O. \& Lester, L. J. (1977) Evolution 31, 836-842.

47. Hebert, P. D. N., Ward, R. D. \& Weider, L. J. (1988) Evolution 42, 147-160.

48. Tibayrenc, M. \& Brenière, S. F. (1988) Mem. Inst. Oswaldo Cruz 83, 249-255.

49. Gibson, W. C. (1986) Parasitol. Today 2, 255-257.

50. Milkman, R. (1973) Science 182, 1024-1026.

51. Selander, R. K. \& Levin, B. R. (1980) Science 210, 545-547. 